\title{
In vitro bioavailability studies on phytochemical profile and antioxidant activity potential of Clematis viticella $\mathrm{L}$.
}

\author{
Esra ACAR-ŞAH 1 (D), Engin CELEP 2 * (D), Erdem YEŞILADA 2 (D) \\ 1 Department of Pharmacognosy, School of Pharmacy, İstanbul Medipol University, Beykoz 34815 İstanbul, Turkey. \\ 2 Department of Pharmacognosy, Faculty of Pharmacy, Yeditepe University, Ataşehir 34755 İstanbul, Turkey. \\ * Corresponding Author. E-mail: ecelep@yeditepe.edu.tr (E.C.); Tel. +90-216-578 0558.
}

Received: 17 September 2018 / Revised: 17 December 2018/ Accepted: 19 December 2018

\begin{abstract}
Since biotransformation processes generally affect the biological activities of phytochemical compounds, bioavailability is one of the primary steps in determining the potency of the activity. Previous studies have shown that in vitro antioxidant capacity of phytochemicals cannot completely reflect real health benefits. Clematis species (Ranunculaceae) are used to eliminate the symptoms of many diseases including particularly in the treatment of rheumatic diseases in Turkey, however the number of studies conducted is limited. In the light of this information, the total phytochemical profile of the extract of aerial parts of C. viticella prepared with $80 \%$ methanol and the gastrointestinal digestion products and the antioxidant activity profile were evaluated by subjecting them to the in vitro simulation model of the human digestive tract in the study. It was observed that both total phytochemical content and antioxidant activity decreased after simulated human digestion. Moreover, this study was shown potential bioaccessibility and bioavailability of total phenol, phenolic acid, flavonoid, and saponin content found in the aerial parts of Clematis viticella were reduced. Consequently, these indicate that it can result from the complicated interaction of compounds in the plant matrix in an in vitro simulated human digestion.
\end{abstract}

KEYWORDS: Clematis viticella L.; Ranunculaceae; phenolic profile; antioxidant activity; in vitro digestion simulation model; bioavailability; bioaccessibility.

\section{INTRODUCTION}

The genus Clematis is a broad genus within Dicotyledons and has about 300 species worldwide. Clematis viticella, one of five Clematis species, growing naturally in Turkey, are known by local names such as "yakiotu", "yakmuk", "karanane" and "delibağ" [1, 2]. The plant, belonging to Ranunculaceae family, is a perennial woody and climbing plant [3].

Clematis species have traditionally been used as a prophylactic and/or therapeutic remedy against a wide range of ailments including syphilis, gout, malaria, dysentery, rheumatism, asthma, insomnia, insect bites, eye infections, toothache, gonorrhea, blisters, ulcers, bone illnesses, dermatological disorders, varicosity and beriberi since ancient times [4]. In addition to ethnobotanical data, in vitro and in vivo pharmacological studies showed that these species have a wide array of effects such as anti-arthritic [5], anti-inflammatory [5], antipyretic [5], antimicrobial [6], antioxidant [7], anticancer [8], diuretic [9], hypotensive [10] and antiobesity [11]. These activities are thought to result from simple phenolic compounds, flavonoids, alkaloids, saponins and anemonins contained in plants [4].

Clematis viticella $\mathrm{L}$. aerial parts are also used traditionally in Turkey to alleviate the symptoms of many diseases, particularly of rheumatic diseases; however, the number of phytochemical and pharmacological studies conducted is scarce [5].

The correlation between phenolic compounds and antioxidant activity was supported by many studies using different methods. Nevertheless, it has been shown that in vitro antioxidant capacity of phytochemicals cannot entirely reflect factual health benefits. Since biotransformation processes generally influence the biological activities of antioxidant compounds, for a complete evaluation of bioavailability of phytochemicals, information is needed concerning their pharmacokinetic properties such as absorption, metabolism, distribution and excretion from the organism. To paraphrase, molecules are needed to be bioaccessible so as to demonstrate their biotransformation and bioactivity. That being said, conducting in vivo and clinic

How to cite this article: Acar-Şah E, Celep E, Yeşilada E. In vitro bioavailability studies on phytochemical profile and antioxidant activity potential of Clematis viticella L. J Res Pharm. 2019; 23 (2): 326-335. 
investigations are complicated, technically difficult, expensive, and can reveal ethic conditions, as well. Thus, GI digestion is expressed as a significant inceptive step in the analysis of the action potential of compounds. Moreover, the results obtained from them generally correlate with those of in vivo or clinical studies [12-14].

In the light of this information, the total phenol, phenolic acid, flavonoid, proanthocyanidin and saponin profiles of the aerial parts of C. viticella prepared with $80 \%$ methanol and the gastrointestinal digestion products and the antioxidant activity profile were evaluated by subjecting it to the in vitro simulation model of the human digestive tract and were demonstrated by different mechanisms in this study. By this way, we aimed to demonstrate the bioaccessibility and bioavailability of the phytochemical components in the mentioned extract. Any possible changes in the antioxidant capacity, which might occur subsequent to in vitro gastrointestinal digestion were also screened for a complete evaluation of the activity profile.

\section{RESULTS}

\subsection{Quantification of the phytochemical profile of the samples}

The total phytochemical content of CVME and the gastrointestinal digestion products was given in Table 1 according to the simulation process of in vitro human digestion. While CVME had the highest total phenolic content before digestion simulation, this content was slightly decreased after the gastric phase of digestion. Furthermore, it was significantly decreased after the intestinal digestion. It was also observed that phenolic acid content of CVME decreased throughout gastrointestinal digestion, but most of it passed through a gastric phase of digestion. IN+OUT fraction seemed to possess the lowest value. Total flavonoid content of CVME increased after the gastric phase of digestion. However, this increase was not significant $(p>0.05)$.

Table 1. Total phytochemical profile of $\mathrm{CVME}^{*}$ before and after simulated human digestion.

\begin{tabular}{|c|c|c|c|c|}
\hline Name of the analysis & NDE & PG & IN & IN+OUT \\
\hline lic Content ${ }^{A}$ & 113. & & $92+$ & \\
\hline Total Phenolic Acid Content ${ }^{B}$ & $55 \pm 0.91^{a}$ & $41.36 \pm 0 \mathrm{~b}$ & $18.03 \pm 3.67 c$ & $15.61 \pm 1.05^{c}$ \\
\hline Total Flavonoid Content ${ }^{C}$ & $21.16 \pm 2.46^{\mathrm{a}}$ & $24.29 \pm 1.45^{\mathrm{a}}$ & $6.98 \pm 0.57 b$ & $9.37 \pm 0.27 \mathrm{~b}$ \\
\hline Total Sapo & $131.97 \pm 0.58^{a}$ & $3.63 \pm 0.58^{b}$ & $30.3 \pm 1^{c}$ & $42.97 \pm 0.58^{d}$ \\
\hline \multicolumn{5}{|c|}{$\begin{array}{l}\text { A Results were expressed as the mean of triplicates } \pm \text { standard deviation (S.D.) and as } \mathrm{mg} \text { gallic acid equivalents (GAE) in } \\
1 \mathrm{~g} \text { dry extract. } \\
\text { B Results were expressed as the mean of triplicates } \pm \text { standard deviation (S.D.) and as } \mathrm{mg} \text { caffeic acid equivalents (CAE) } \\
\text { in } 1 \mathrm{~g} \text { dry extract. } \\
\text { C Results were expressed as the mean of triplicates } \pm \text { standard deviation (S.D.) and as } \mathrm{mg} \text { quercetin equivalents (QE) in } 1 \\
\text { g dry extract. } \\
\text { D Results were expressed as the mean of triplicates } \pm \text { standard deviation (S.D.) and as mg escin equivalents (EE) in } 1 \mathrm{~g} \text { dry } \\
\text { extract. } \\
\text { E The abbreviations for samples are ND: non-digested, PG: postgastric, IN: serum available, OUT: colon available } \\
\text { a-d Values with different letters within a row were significantly different (p }<0.05 \text { ) } \\
\text { * CVME: } 80 \% \text { methanolic extract of Clematis viticella L. aerial parts. }\end{array}$} \\
\hline
\end{tabular}

The extract was found to have high saponin content prior to in vitro gastrointestinal digestion. However, significant decrease in PG and IN fractions was observed after digestion simulation. The content of total proanthocyanidins in both extract and digestive products was measured by using the vanillin- $\mathrm{HCl}$ method yet could not be determined.

The bioavailability values of the CVME fractions were shown in Table 2. Total phenolic contents $(55.25 \%)$ possessed better bioavailability indexes, when compared with total phenolic acids, flavonoids and saponins. The lowest index belonged to total saponins (22.96\%).

The bioaccessibility results of the CVME fractions were shown in Table 2. As in the case with bioavailability results, it was also observed that phenolic compounds have the highest index in bioaccessibility results. These compounds were followed by flavonoids, saponins and phenolic acids, respectively. 
Table 2. Bioavailability and bioaccessibility results of CVME*.

\begin{tabular}{lcc}
\hline Name of the analysis & $\begin{array}{c}\text { Bioavailability index (BAvI) } \\
\text { (IN/ND) X 100 }\end{array}$ & $\begin{array}{c}\text { Bioaccessibility index (BAcI) } \\
\text { [(IN+OUT)/ND] X 100 }\end{array}$ \\
\hline Total Phenolic Content & $55.25 \%$ & $59.87 \%$ \\
Total Phenolic Acid Content & $32.78 \%$ & $28.38 \%$ \\
Total Flavonoid Content & $32.99 \%$ & $44.28 \%$ \\
Total Saponin Content & $22.96 \%$ & $32.56 \%$ \\
\hline
\end{tabular}

* CVME: $80 \%$ methanolic extract of Clematis viticella L. aerial parts.

\subsection{Estimation of in vitro antioxidant capacity}

DPPH radical-scavenging activity of $80 \%$ methanolic extract of Clematis viticella aerial parts were given in Table 3 according to the simulation process of in vitro human digestion. The results were expressed as "half maximal effective concentration" $\left(\mathrm{EC}_{50}\right)$. Although the non-digested fraction of CVME showed high DPPH radical-scavenging activity, the BHT used as reference substance showed the highest activity. The metal reducing activity of the extract significantly decreased both after the gastric phase of digestion and after the intestinal digestion. In addition, the free radical scavenging activity of the bioaccessible fraction (IN+OUT sample) was significantly higher than bioavailable fraction (IN sample). The DMPD radical-scavenging activity of CVME also showed similar results to DPPH radical-scavenging activity. These radical scavenging tests were used in order to assess the influence of samples on free radicals. Table 3 summarizes the results of these tests.

Table 3. In vitro antioxidant activity potential of $\mathrm{CVME}^{*}$ before and after simulated human digestion

\begin{tabular}{lcccc}
\hline $\begin{array}{l}\text { Name of the } \\
\text { analysis }\end{array}$ & NDE $^{\mathrm{E}}$ & PG & IN & IN+OUT \\
\hline $\begin{array}{l}\text { DPPH radical- } \\
\text { scavenging }\end{array}$ & $395.64 \pm 22.64^{\mathrm{a}}$ & $488.85 \pm 42.88^{\mathrm{b}}$ & $922.56 \pm 22.6^{\mathrm{c}}$ & $718.45 \pm 12.31^{\mathrm{d}}$ \\
$\begin{array}{l}\text { activity } \\
\text { DMPD radical- }\end{array}$ & $60.55 \pm 1.19^{\mathrm{a}}$ & $54.80 \pm 3.28 \mathrm{~b}$ & $33.58 \pm 1.5^{\mathrm{c}}$ & $35.37 \pm 0.69 \mathrm{c}$ \\
$\begin{array}{l}\text { scavenging } \\
\text { activity }\end{array}$ & & & & \\
$\begin{array}{l}\text { Ferric reducing } \\
\text { antioxidant }\end{array}$ & $974.05 \pm 7.11^{\mathrm{a}}$ & $715.68 \pm 41.68^{\mathrm{b}}$ & $375.71 \pm 50.6^{\mathrm{c}}$ & $369.18 \pm 3.77^{\mathrm{c}}$ \\
$\begin{array}{l}\text { powerc } \\
\text { Cupric reducing } \\
\text { antioxidant } \\
\text { capacity }\end{array}$ & $240.01 \pm 3.02^{\mathrm{a}}$ & $192.76 \pm 3.45^{\mathrm{b}}$ & $98.78 \pm 0.87^{\mathrm{c}}$ & $97.5 \pm 0.73^{\mathrm{c}}$ \\
$\begin{array}{l}\text { Total } \\
\text { antioxidant } \\
\text { capacity }\end{array}$ & & & & \\
\hline
\end{tabular}

P.S. 1) $\mathrm{EC}_{50}$ value of the reference compound "butylated hydroxytoluene (BHT)" in DPPH scavenging activity is found to be $77.84 \pm 0.5$. 2) FRAP activity of the reference compound "butylated hydroxytoluene (BHT)" is found to be $2353.18 \pm$ $54.54 \mu \mathrm{M} \mathrm{FeSO}_{4}$ eq. in $1 \mathrm{~g}$ dry extract.

A Results were expressed as the mean of triplicates \pm standard deviation (S.D.) and DPPH activity was expressed as EC 50 in $\mu \mathrm{g} / \mathrm{mL}$ equivalents.

в Results were expressed as the mean of triplicates \pm standard deviation (S.D.) and as mg Trolox equivalents (TE) in $1 \mathrm{~g}$ dry extract.

C Results were expressed as the mean of triplicates \pm standard deviation (S.D.) and as $\mu \mathrm{M} \mathrm{FeSO}_{4}$ equivalents in 1 g dry extract.

D Results were expressed as the mean of triplicates \pm standard deviation (S.D.) and as mg ascorbic acid equivalents (AAE) in $1 \mathrm{~g}$ dry extract.

E The abbreviations for samples are ND: non-digested, PG: postgastric, IN: serum available, OUT: colon available

a-d Values with different letters within a row were significantly different $(p<0.05)$

* CVME: $80 \%$ methanolic extract of Clematis viticella L. aerial parts. 
Metal-related antioxidant capacities were also measured in this study. The results of both ferric reducing antioxidant power (FRAP) and cupric ion reducing antioxidant capacity (CUPRAC) assays were shown in Table 3. CVME and digestive products had perceptible ferric reducing antioxidant power in comparison with the reference compound, BHT. A major part of CVME fractions (73.47\%) passed through gastric phase of digestion. A small portion (38.57\%) passed into serum phase. Results of both non-digested and digested samples in the cupric reducing capacity assay displayed similarity with those ferric reducing power.

Although Clematis viticella had the highest total antioxidant capacity before digestion simulation, this content was slightly decreased after the gastric phase of digestion. Moreover, it was significantly decreased after the intestinal digestion.

\section{DISCUSSION}

Recent studies have focused on antioxidant compounds found in plants, and their potential roles in the protection of body against oxidative stress. The main natural antioxidants present in plants and protecting the human body from harmful free radicals are mainly vitamins (vitamins A, C and E), flavonoids, carotenoids and polyphenols. Many studies have also shown that phenolic compounds have significant antioxidant activities assisting the body's natural antioxidant defense mechanism [15-17].

Correlation between antioxidant activity and phenolic compounds was supported by uncountable number of work using different methods. However, it was stated that in vitro antioxidant assays might not be sufficient to fully expose the real health benefits of phytochemicals. Thus, simulation process of in vitro human digestion is expressed as an important initial step in the analysis of the activity profile of phytochemicals. Various studies indicated that the biological properties of phytochemicals found in the plants are directly influenced by the metabolism, bioaccessebility and bioavailability of these molecules in the body. To put it in another way, molecules are needed to be bioaccessible so as to exhibit their bioactivity after biotranformation. The bioavailability of phytochemicals is associated with diversified factors which include chemical state of compound, the molecular weight, differences in enzymatic digestion, absorption, plant matrix, polarity, interactions with macromolecules, etc. GI digestion is the most crucial factor among them. Bioactive ingredients, especially of natural origin, can be exposed to chemical and structural changes that might cause variations in the biological activity during the digestion process. Whereby, tracing the changes occurring throughout digestion, for instance, enzymatic activity, altered $\mathrm{pH}$ and mechanical action is significant in the evaluation of bioactivity and bioavailability $[13,14,18]$.

It is evident that the in vitro simulation method cannot contain all stages of the human digestive system the reason is that it does not completely forge the active transportation processes. Nevertheless, when compared with in vivo and clinical investigations, it is simpler, cheaper and more reproducible. Moreover, the method enables the scanning of a broad range of samples and experimental conditions. It also permits the estimation of phytochemical modifications interrelated to the GI digestion [13, 19, 20].

As mentioned before, Clematis species (Ranunculaceae) are used to eliminate the symptoms of many diseases including particularly in the treatment of rheumatic diseases in Turkey. Among them, Clematis viticella L. aerial parts are widely employed traditionally in rheumatic complaints in Kocaeli and its vicinity, but the number of studies conducted is scarce [5]. The chemical composition of ethanolic extract of Clematis viticella aerial parts was investigated recently by Kirmızibekmez et al. [21]. In that study, flavonoid glycosides, phenolic acids and one phenylethanoloid derivative were isolated. Later, the compounds isolated from $C$. viticella were shown to be anti-inflammatory by using different markers. Apart from this study, there are no biological activity and phytochemical studies on Clematis viticella according to our literature survey. In the light of these studies, we planned to appraise the phytochemical profile and the antioxidant capacity of Clematis viticella aerial parts growing in Turkey, before and after simulation model of in vitro human digestion.

Total phenol, phenolic acid, flavonoid, proanthocyanidin and saponin contents of Clematis viticella were evaluated before and after simulated human digestion. However, the content of total proanthocyanidin in both extract and digestive products could not be determined, most probably due to lack of sufficient amount to be detected. As expected, total phenol, phenolic acid, flavonoid and saponin contents were found the most in ND fractions, while they were found the least in IN and IN+OUT fractions and no significant difference was observed between IN and IN+OUT fractions, except total saponin content. Total saponin content was strikingly reduced in bioavailable IN fraction when compared to the IN+OUT fraction [22]. This sharp decrease in total contents can be related to $\mathrm{pH}$ changes in the digestion medium, particularly the alkaline $\mathrm{pH}$ of the intestines. The other cause of the change is the impact of GI digestive enzymes because they enable the release of phytochemicals from the sample matrix. Further different studies demonstrated that phenolic 
compounds are not stable and they are exposed to hydrolysis after GI digestion [20, 23]. Several authors also reported that the total phenol content of different plant extracts is reduced after simulated human digestion $[24,25]$. Conversely, there are also studies showing that total phenol content increases after intestinal phase [26]. These variations might result from the diversities in the digestion simulation process or directly from the studied sample.

Antioxidant capacities of both digested and non-digested samples were demonstrated using different methods. Experiments with different mechanisms are required to fully evaluate the antioxidant activity. The antioxidant activities of different Clematis species (C. armandii [27], C. chinensis [28], C. flammula [29], C. rehderiana [30] and C. trichotoma [7]) were investigated using various methods. Different extracts from these plants exerted significant in vitro antioxidant activity. However, in none of these in vitro studies the GI digestion process was taken into consideration.

The DPPH radical-scavenging activity of the sample slightly decreased after the gastric phase of the digestion. Nonetheless, the activity was significantly reduced after intestinal digestion and bioavailable IN fraction showed the least activity. The results of DMPD radical-scavenging activity were almost identical to those of DPPH radical-scavenging activity. It was also found the least in IN fraction. Similarly, the FRAP and CUPRAC activities of the samples were also reduced following the simulated digestion process. Meanwhile, metal reducing activities of the samples were found the least in IN+OUT fractions. The results also exhibited a reduction in the total antioxidant capacity (TOAC) of the samples after simulation process of in vitro human digestion. The reduction of antioxidant activity after in vitro digestion simulation was shown by different studies $[19,23,31]$.

When all the results are considered, the decrease in the antioxidant activity might be derived from the lower concentration of phenolic compounds after the simulation of GI digestion compared to nondigested samples. $\mathrm{pH}$ alterations might induce the changes in the antioxidant activity, as well $[23,31]$. Moreover, the interaction of antioxidant phenolics with other compounds of the samples such as minerals, vitamins, volatile compounds might also culminate in changes in their bioactivity and bioavailability [25, 32].

Clematis viticella should be considered as a good source of bioaccessible antioxidants and related phytochemical substances in phytotherapy which is a form of complementary therapy applied through the use of drugs and preparations made from drug to assist in treatment to protect against diseases to heal and alleviate diseases.

Taking into consideration, one can reach the result that the simulation process of in vitro human digestion significantly affected the antioxidant capacity of Clematis viticella. Moreover, this study showed potential bioavailability and bioaccessibility of total phenol, phenolic acid, flavonoid, and saponin contents found in the aerial parts of Clematis viticella. The results indicated that both phenolic content and antioxidant activity decreased after simulated human digestion. Furthermore, it should be considered that non-phenolic compounds conduce to antioxidant capacity. In conclusion, these results can be interpreted as these decrements might result from the complicated interaction of compounds in the plant matrix in an in vitro simulated human digestion.

\section{CONCLUSION}

Consequently, the data obtained from this study has provided a scientific explanation for the ethnobotanical use of Clematis viticella by both the activity and the chemical analyses. In addition, the antioxidant activity profile and phytochemical content of Clematis viticella are investigated for the first time in this study by subjecting it to the in vitro simulation model of the human digestive tract. According to the results obtained, it is shown that Clematis viticella has high antioxidant activity, since contains high phenolic compounds and saponins. This study will be a pioneer for future researches which will be held in order to investigate the antioxidant activity mechanism or the identification of effective components of Clematis viticella.

\section{MATERIALS AND METHODS}

\subsection{Chemicals}

All chemicals, enzymes and references used in the experiment protocols were purchased from Sigma Chemical Co. (St. Louis, MO, USA). The quality of all chemicals was of analytical grade. 


\subsection{Plant samples}

The aerial parts of Clematis viticella L. were collected from Şehitler village, İnegöl, Bursa, Turkey on 15 July, 2017. The authentication of the plant material was conducted by one of the authors (E.Y.) and a voucher specimen was deposited in the herbarium of Faculty of Pharmacy, Yeditepe University, İstanbul, Turkey. (Herbarium No: YEF17013)

The dried and powdered aerial parts of Clematis viticella $(156 \mathrm{~g}$ ) were macerated with $1000 \mathrm{~mL}$ of $80 \%$ aqueous $\mathrm{MeOH}$ in the dark for 3 days at room temperature. The resulting total extract was filtered, and methanol was completely removed in a rotary evaporator under reduced pressure. The remaining part was then lyophilized (the yield was $22.10 \mathrm{~g}, 14.17 \%$ ). The lyophilized extract was dissolved in water prior to experimental studies (CVME) (nondigested samples: ND).

\subsection{In vitro simulation process of human digestion}

The simulation process of in vitro human digestion consisting of two consecutive steps was modified by Celep et al. from a previously reported study $[19,20]$. The simulated stomach solution was composed of pepsin enzyme and $\mathrm{NaCl}$ dissolved in distilled water, $\mathrm{pH}$ of the solution was adjusted to 2 with $\mathrm{HCl}$. An aliquot of sample solution was taken and the volume was completed to $20 \mathrm{~mL}$ with the simulated stomach solution. The mixture was incubated at $37^{\circ} \mathrm{C}$ in a shaking water bath for 2 hours. At the end of this step, the mixture was instantly cooled down in an ice bath and then an aliquot was taken as a representative of "post-gastric" sample (PG) and kept at $-20^{\circ} \mathrm{C}$. A segment of cellulose dialysis tubing (molecular weight cut off $12 \mathrm{kDa}$ ) containing sufficient $\mathrm{NaHCO}_{3}$ was placed inside the beaker. The mixture was placed at $37^{\circ} \mathrm{C}$ in a shaking water bath for 15 minutes. After that, a mixture of pancreatin $(4 \mathrm{mg} / \mathrm{mL})$ and bile salts $(25 \mathrm{mg} / \mathrm{mL})$ were added to the medium and the solution was incubated under the same conditions for an additional 2 hours. In the later process, the same procedures were performed without a cellulose tube. At the end of the incubation process, the solution left outside the dialysis tubing was referred as the OUT sample representing material that remained in the gastrointestinal tract (colon-available) and the solution that managed to diffuse into the dialysis tubing was taken as the IN sample (serum-available). The solution obtained from the later process is referred as IN+OUT since it contains both compartments. At the end of all processes, the $\mathrm{pH}$ of the solutions was adjusted to 2 to deactivate all enzymatic process and to improve storage conditions. Besides, all of the samples were centrifuged for 20 minutes at $15.000 \mathrm{rpm}$ in order to precipitate the bile acids. They were kept at $-20^{\circ} \mathrm{C}$ for further analysis no longer than one week.

\subsection{Quantitative assessment of phytochemical profile}

\subsubsection{Total phenolic content}

The total phenolic content of the samples was determined according to the method of Singleton and Rossi [33]. $75 \mu \mathrm{L}$ of $\mathrm{Na}_{2} \mathrm{CO}_{3}$ and $100 \mu \mathrm{L}$ of Folin-Ciocalteu Reagent were added to $20 \mu \mathrm{L}$ of freshly diluted each sample. Then the composite was left to incubate in the dark at room temperature for 30 minutes. The absorbance was measured spectrophotometrically at $690 \mathrm{~nm}$ using 96-well microplate reader. The total phenolic content of the samples was expressed as mg gallic acid equivalents (GAE) in $1 \mathrm{~g}$ dry extract.

\subsubsection{Total phenolic acid content}

The total phenolic acid content of the samples was detected spectrophotometrically with respect to the method declared by Mihailović et al. in 2016 [34]. $1 \mathrm{~mL}$ of each of sample, Arnow reagent, $0.1 \mathrm{M} \mathrm{HCl}$ and $1 \mathrm{M}$ $\mathrm{NaOH}$ solutions were mixed. Later, the eventual volume was adjusted to $10 \mathrm{~mL}$ with distilled water. The absorbance of samples was measured immediately at $490 \mathrm{~nm}$. The total phenolic acid content of the samples was stated as caffeic acid equivalents (CAE) in $1 \mathrm{~g}$ dry extract.

\subsubsection{Total flavonoid content}

The total flavonoid content of the samples was calculated according to the aluminum chloride colorimetric method developed by Woisky and Salatino [35]. $50 \mu \mathrm{L}$ of samples were mixed with $150 \mu \mathrm{L}$ of $75 \%$ ethanol, $10 \mu \mathrm{L}$ of $10 \%$ aluminum chloride solution, $10 \mu \mathrm{L}$ of $1 \mathrm{M}$ potassium acetate. The mixture was incubated in the dark at room temperature for 30 minutes. The absorbance was read spectrophotometrically at $405 \mathrm{~nm}$. The results were expressed as quercetin equivalents $(\mathrm{QE})$ in $1 \mathrm{~g}$ dry extract. 


\subsubsection{Total proanthocyanidin content}

The total proanthocyanidin content of the samples was explored with regard to the vanillin- $\mathrm{HCl}$ method emphasized by Ariffin et al. [36]. $2.5 \mathrm{~mL}$ of $1 \%$ vanillin and $2.5 \mathrm{~mL}$ of $9 \mathrm{M} \mathrm{HCl}$ were added to $1 \mathrm{~mL}$ of sample in a capped glass tube. The mixture was allowed to incubate in the dark for 20 minutes at $30^{\circ} \mathrm{C}$. The absorbance was read spectrophotometrically at $492 \mathrm{~nm}$. The total proanthocyanidin content of the samples was expressed as (-)-epicatechin equivalents (ECE) in $1 \mathrm{~g}$ dry extract.

\subsubsection{Total saponin content}

The total saponin content of the samples was performed according to the vanillin-sulfuric acid method developed by Hiai et al. [37]. $0.5 \mathrm{~mL}$ of $8 \%$ vanillin and $5 \mathrm{~mL}$ of $72 \% \mathrm{H}_{2} \mathrm{SO}_{4}$ were added to $0.5 \mathrm{~mL}$ of samples in a closed-cap polypropylene tube, respectively. The mixture was incubated at $70{ }^{\circ} \mathrm{C}$ in $10 \mathrm{~min}$. The tubes are taken immediately to the ice bath and cooled down to room temperature. The absorbance was read spectrophotometrically at $560 \mathrm{~nm}$. The results were clarified as escin equivalents (EE) in $1 \mathrm{~g}$ dry extract.

\subsection{Determination of potential bioavailability index of phytochemical compounds}

Bioavailability is the degree and the rate at which compounds can reach the effect site within the body. The bioavailability indexes of the CVME fractions were determined as the ratio of the activity in non-digested (ND) samples to the activity in IN samples, representing the serum and colon-available contents [38].

$$
\text { Bioavailability index }(\mathrm{BAvI})=(\mathrm{IN} / \mathrm{ND}) \times 100
$$

\subsection{Determination of potential bioaccessibility index of phytochemical compounds}

Bioaccessibility is an important initial step for compounds to display their biological activities. The bioaccessibility indexes of the CVME fractions were determined as the ratio of the activity in non-digested (ND) samples to the activity in IN+OUT samples, representing the serum and colon-available contents [26].

$$
\text { Bioaccessibility index }(\mathrm{BAcI})=[(\mathrm{IN}+\mathrm{OUT}) / \mathrm{ND}] \times 100
$$

\subsection{Estimation of antioxidant activity based on free radical-scavenging activity}

\subsubsection{DPPH (2,2-diphenyl-1-picrylhydrazyl) radical-scavenging activity}

The scavenging activity of the samples against DPPH radical was expressed by using the method described by Akter et al. [39, 40]. $25 \mu \mathrm{L}$ of samples were separately added to $200 \mu \mathrm{L} 0.1 \mathrm{mM}$ DPPH solution prepared in methanol just before use. The mixture was incubated at room temperature in the dark for 50 minutes. The absorbance was calculated at $540 \mathrm{~nm}$. MeOH was used in the control group and butylated hydroxy toluene (BHT) was used as the reference material.

\subsubsection{DMPD (N, N'-dimethyl-p-phenylenediamine) radical-scavenging activity}

The scavenging activity of the samples against DMPD radical was expressed by using the method described by Fogliano et al. in 1999 [41]. $15 \mu \mathrm{L}$ of samples were separately added to $210 \mu \mathrm{L}$ of the DMPD solution prepared just before use. The mixture was incubated at room temperature in the dark for 50 minutes. The absorbance was measured at $492 \mathrm{~nm}$. The results were given as $\mathrm{mg}$ Trolox equivalent (TE) per g material.

\subsection{Estimation of antioxidant activity based on metal-related activity}

\subsubsection{Ferric reducing antioxidant power (FRAP)}

FRAP activity was performed according to a method described by Benzie and Strain [42]. $10 \mu \mathrm{L}$ of samples and $30 \mu \mathrm{L}$ of distilled water were mixed with working FRAP reagent in a microplate. The mixture was incubated at $37^{\circ} \mathrm{C}$ for 30 minutes. Later, the absorbance was recorded at $593 \mathrm{~nm}$ using a 96-well microplate reader. Butylated hydroxy toluene was used as the reference substance. The results were expressed as $\mu \mathrm{M}$ $\mathrm{FeSO}_{4} .7 \mathrm{H}_{2} \mathrm{O}$ per g material.

\subsubsection{Cupric reducing antioxidant capacity (CUPRAC)}

CUPRAC activity was recorded according to the method found by Apak et al. with some modifications [43]. $85 \mu \mathrm{L}$ of each of $10 \mathrm{mM} \mathrm{CuSO}_{4}, 7.5 \mathrm{mM}$ neocuproine, and $1 \mathrm{M}$ ammonium acetate buffer (pH 7.0) solutions were mixed in a microplate. Later, $51 \mu \mathrm{L}$ of distilled water and $43 \mu \mathrm{L}$ of samples were added respectively. The 
mixture was incubated at room temperature for 1 hour. After the incubation period, the absorbance was read at $450 \mathrm{~nm}$. The results were given as $\mathrm{mg}$ ascorbic acid equivalent (AAE) per $\mathrm{g}$ material.

\subsection{Determination of total antioxidant capacity by phosphomolybdenum method (TOAC)}

The total antioxidant capacities of the samples were measured with regard to the phosphomolybdenum method found by Prieto et al. with small modifications [44]. $300 \mu \mathrm{L}$ of the reagent solution were mixed with $30 \mu \mathrm{L}$ of warrantably diluted samples. The microplate containing the mixture was incubated at $95{ }^{\circ} \mathrm{C}$ for 90 minutes in a water bath. After the incubation period, the samples were cooled to room temperature, and the absorbance was read at $690 \mathrm{~nm}$ using a 96-well microplate reader. The results were given as mg ascorbic acid equivalent (AAE) per g material.

\subsection{Statistics}

The experiments were performed in triplicate. The results were assessed as mean \pm standard deviation. Statistical comparisons were made using one-way analysis of variance (ANOVA) followed by StudentsNewman- Keuls post hoc test for multiple comparisons. In addition, Pearson correlation coefficients were calculated. Statistically significant difference was detected as $\mathrm{p}<0.05$.

Acknowledgement: Authors are grateful to Ms. Selin Akyüz and Mr. Yiğit İnan for their invaluable assistance during this study.

Author contributions: Concept - E.A., E.C.; Design - E.A., E.C., E.Y.; Supervision - E.Y.; Materials - E.A., E.C., E.Y.; Data Collection and/or Processing - E.A., E.C; Analysis and/or Interpretation - E.A., E.C Literature Search - E.A.; Writing - E.A.; Critical Reviews - E.A., E.C., E.Y.

Conflict of interest statement: The authors declared no conflict of interest.

\section{REFERENCES}

[1] Baytop T, Türkiye' de Bitkiler İle Tedavi, Geçmişte ve Bugün, Nobel Tıp, İstanbul, Turkey 1999.

[2] Küpeli E. PhD Thesis. Clematis vitalba L. bitkisinin romatizma tedavisindeki etkisi üzerinde çalışmalar. Department of Pharmacognosy, Faculty of Pharmacy, Gazi University, Ankara, Turkey, 2004.

[3] Davis PH. Clematis. In: Davis PH. (Eds). Flora of Turkey and the East Aegean Islands. Edinburgh University Press, Edinburgh, 1984, pp.138-140.

[4] Chawla R, Kumar S, Sharma A. The genus Clematis (Ranunculaceae): chemical and pharmacological perspectives. J Ethnopharmacol. 2012; 143: 116-150. [CrossRef]

[5] Yesilada E, Küpeli E. Clematis vitalba L. aerial part exhibits potent anti-inflammatory, antinociceptive and antipyretic effects. J Ethnopharmacol. 2007; 110: 504-515. [CrossRef]

[6] Kyung KH, Woo Y, Kim DS, Park HJ, Kim YS. Antimicrobial activity of an edible wild plant, Apiifolia virgin's bower (Clematis apiifolia DC). Food Sci Biotechnol. 2007; 16: 1051-1054.

[7] Hung TM, Thuong PT, Bae K. Antioxidant effect of flavonoids isolated from the root of Clematis trichotoma Nakai. Korean J Med Crop Sci. 2005; 13(5): 227-232.

[8] Peng H, Lv H, Wang Y, Liu YH, Li CY, Meng L, Chen F, Bao JK. Clematis montana lectin, a novel mannose - binding lectin from traditional Chinese medicine with antiviral and apoptosis - inducing activities. Peptides. 2009; 30: 18051815. [CrossRef]

[9] Álvarez ME, María AOM, Villegas O, Saad JR. Evaluation of diuretic activity of the constituents of Clematis montevidensis Spreng. (Ranunculaceae) in rats. Phyther Res. 2003;17:958-960. [CrossRef]

[10] Ho CS, Wong YH, Chiu KW. The hypotensive action of Desmodium styracifolium and Clematis chinensis. Am J Chin Med. 1989; 17(3-4): 189-202. [CrossRef]

[11] Marrelli M, Loizzo MR, Nicoletti M, Menichini F, Conforti F. Inhibition of key enzymes linked to obesity by preparations from Mediterranean dietary plants: effects on a-amylase and pancreatic lipase activities. Plant Foods Hum Nutr. 2013; 68: 340-346.

[12] Hur SJ, Lim BO, Decker EA, McClements DJ. In vitro human digestion models for food applications. Food Chem. 2011; 125: 1-12. [CrossRef] 
[13] Alminger M, Aura AM, Bohn T, Dufour C, El SN, Gomes A, Karakaya S, Martinez-CuestaMC, McDougall GJ, Requena T, Santos CN . In vitro models for studying secondary plant metabolite digestion and bioaccessibility. Compr Rev Food Sci Food Saf. 2014; 13: 413-436. [CrossRef]

[14] Celep E, Akyüz S, İnan Y, Yesilada E. Assessment of potential bioavailability of major phenolic compounds in Lavandula stoechas L. ssp. stoechas. Ind Crops Prod. 2018; 118: 111-117. [CrossRef]

[15] Floyd RA. Role of oxygen free radicals in carcinogenesis and brain ischemia. FASEB J. 1990; 4(9): $2587-2597$. [CrossRef]

[16] Koşar M, Göger F, Baser KHC. In vitro antioxidant properties and phenolic composition of Salvia virgata Jacq. from Turkey. J Agric Food Chem. 2008; 56: 2369-2374.

[17] Rice-Evans C, Miller NJ, Paganga G. Antioxidant properties of phenolic compounds. Trends Plant Sci. 1997; 2(4): 152159. [CrossRef]

[18] Villanueva-Carvajal A, Bernal-Martínez LR, García-Gasca MT, Dominguez-Lopez A. In vitro gastrointestinal digestion of Hibiscus sabdariffa L.: the use of its natural matrix to improve the concentration of phenolic compounds in gut. LWT - Food Sci Technol. 2013; 51: 260-265. [CrossRef]

[19] Celep E, Charehsaz M, Akyüz S, Acar ET, Yesilada E. Effect of in vitro gastrointestinal digestion on the bioavailability of phenolic components and the antioxidant potentials of some Turkish fruit wines. Food Res Int. 2015; 78: 209-215. [CrossRef]

[20] McDougall GJ, Fyffe S, Dobson P, Stewart D. Anthocyanins from red wine - their stability under simulated gastrointestinal digestion. Phytochemistry. 2005; 66: 2540-2548. [CrossRef]

[21] Kirmızıbekmez H, İnan Y, Reis R, Sipahi H, Gören AC, Yesilada E. Phenolic compounds from the aerial parts of Clematis viticella L. and their in vitro anti-inflammatory activities. Nat Prod Res. 2018: 1-4. [CrossRef]

[22] Kim EO, Cha KH, Lee EH, Kim SM, Choi SW, Pan CH, Um BH. Bioavailability of ginsenosides from white and red ginseng in the simulated digestion model. J Agric Food Chem. 2014; 62(41): 10055-10063.

[23] Bouayed J, Hoffmann L, Bohn T. Total phenolics, flavonoids, anthocyanins and antioxidant activity following simulated gastro-intestinal digestion and dialysis of apple varieties: bioaccessibility and potential uptake. Food Chem. 2011; 128: 14-21. [CrossRef]

[24] Siracusa L, Kulisic-Bilusic T, Politeo O, Krause I, Dejanovic B, Ruberto G. Phenolic composition and antioxidant activity of aqueous infusions from Capparis spinosa L. and Crithmum maritimum L. before and after submission to a two-step in vitro digestion model. J Agric Food Chem. 2011; 59(23): 12453-12459.

[25] Wong YH, Tan CP, Long K, Nyam KL. In vitro simulated digestion on the biostability of Hibiscus cannabinus L. seed extract. Czech J Food Sci. 2014; 32(2): 177-181.

[26] Celep E, İnan Y, Akyüz S, Yesilada E. The bioaccessible phenolic profile and antioxidant potential of Hypericum perfoliatum L. after simulated human digestion. Ind Crops Prod. 2017; 109: 717-723. [CrossRef]

[27] Kirby AJ, Schmidt RJ. The antioxidant activity of Chinese herbs for eczema and of placebo herbs - I. J Ethnopharmacol. 1997; 56: 103-108. [CrossRef]

[28] Gan R-Y, Kuang L, Xu X-R, Zhang Y, Xia EQ, Song FL, Li HB. Screening of natural antioxidants from traditional Chinese medicinal plants associated with treatment of rheumatic disease. Molecules. 2010; 15: 5988-5997. [CrossRef]

[29] Atmani D, Chaher N, Berboucha M, Ayauni K, Lounis H, Boudaoud H, Debbache N, Atmani D. Antioxidant capacity and phenol content of selected Algerian medicinal plants. Food Chem. 2009; 112: 303-309. [CrossRef]

[30] Du ZZ, Yang XW, Han H, Cai XH, Luo XD. A new flavone C-glycoside from Clematis rehderiana. Molecules. 2010; 15: 672-679. [CrossRef]

[31] Pandanaboina SC, Kondeti SR, Rajbanshi SL, Kunala PN, Pandanaboina S, Pandanaboina MM, Wudayagiri R. Alterations in antioxidant enzyme activities and oxidative damage in alcoholic rat tissues: Protective role of Thespesia populnea. Food Chem. 2012; 132: 150-159. [CrossRef]

[32] Henning SM, Zhang Y, Rontoyanni VG, Huang J, Lee RP, Trang A, Nuernberger G, Heber D. Variability in the antioxidant activity of dietary supplements from pomegranate, milk thistle, green tea, grape seed, goji, and acai: effects of in vitro digestion. J Agric Food Chem. 2014; 62: 4313-4321. [CrossRef]

[33] Singleton VL, Rossi JAJ. Colorimetry of total phenolics with phosphomolybdic - phosphotungstic acids reagents. Amer J Enol Viticult. 1965; 16: 144-158. 
[34] Mihailović V, Kreft S, Benković ET, Ivanović N, Stanković MS. Chemical profile, antioxidant activity and stability in stimulated gastrointestinal tract model system of three Verbascum species. Ind Crops Prod. 2016; 89: 141-151. [CrossRef]

[35] Woisky RG, Salatino A. Analysis of propolis: some parameters and procedures for chemical quality control. J Apic Res. 1998; 37(2): 99-105. [CrossRef]

[36] Ariffin F, Heong Chew S, Bhupinder K, Karim AA, Huda N. Antioxidant capacity and phenolic composition of fermented Centella asiatica herbal teas. J Sci Food Agric. 2011; 91: 2731-2739. [CrossRef]

[37] Hiai S, Oura H, Nakajima T. Color reaction of some sapogenins and saponins with vanillin and sulfuric acid. Planta Med. 1976; 29: 116-122.

[38] Gayoso L, Claerbout AS, Calvo MI, Cavero RY, Astiasarán I, Ansorena D. Bioaccessibility of rutin, caffeic acid and rosmarinic acid: influence of the in vitro gastrointestinal digestion models. J Funct Foods. 2016; 26: 428-438. [CrossRef]

[39] Akter MS, Ahmed M, Eun JB. Solvent effects on antioxidant properties of persimmon (Diospyros kaki L. cv. Daebong) seeds. Int J Food Sci Technol. 2010; 45: 2258-2264. [CrossRef]

[40] Celep E, Aydin A, Yesilada E. A comparative study on the in vitro antioxidant potentials of three edible fruits: Cornelian cherry, Japanese persimmon and cherry laurel. Food Chem Toxicol. 2012; 50: 3329-3335. [CrossRef]

[41] Fogliano V, Verde V, Randazzo G, Ritieni A. Method for measuring antioxidant activity and its application to monitoring the antioxidant capacity of wines. J Agric Food Chem. 1999; 47: 1035-1040.

[42] Benzie IFF, Strain JJ. The Ferric Reducing Ability of Plasma (FRAP) as a measure of "Antioxidant Power": the FRAP assay. Anal Biochem. 1996; 239: 70-76. [CrossRef]

[43] Apak R, Güçlü K, Özyürek M, Karademir SE. Novel total antioxidant capacity index for dietary polyphenols and vitamins $\mathrm{C}$ and $\mathrm{E}$, using their cupric ion reducing capability in the presence of neocuproine: CUPRAC method. J Agric Food Chem. 2004; 52: 7970-7981.

[44] Prieto P, Pineda M, Aguilar M. Spectrophotometric quantitation of antioxidant capacity through the formation of a phosphomolybdinum complex: specific application to the determination of vitamin E. Anal Biochem. 1999; 269: 337341. [CrossRef] 